\title{
Percepciones sobre la participación activa y la convivencia en una comunidad universitaria*
}

\author{
Perceptions about Active Participation and Coexistence in a \\ University Community \\ Percepções sobre a participação ativa e a convivência em uma \\ comunidade universitária
}

\author{
Flor Ángela TOBÓN MARULANDA* \\ LUIS ALIRIO LÓPEZ GIRALDO ${ }^{* * *}$ \\ RubÉN DARÍO MONTOYA NANCLARES ${ }^{* \star *}$
}

FECHA DE RECEPCIÓN: 30 DE AGOSTO DE 2020. FECHA DE APROBACIÓN: 7 DE ABRIL DE 2021

Doi: https://doi.org/10.12804/revistas.urosario.edu.co/sociojuridicos/a.9572

Para citar este artículo: Tobón Marulanda, F. A., López Giraldo, L. A., E Montoya Nanclares, R. D. (2021). Percepciones sobre la participación activa y la convivencia en una comunidad universitaria. Revista de Estudios SocioJurídicos, 23(2), 221-241. https://doi.org/10.12804/revistas.urosario.edu.co/sociojuridicos/a.9572

\section{RESUMEN}

El objetivo es presentar la reflexión realizada en torno a un estudio hermenéutico exploratorio sobre la percepción de representantes de organizaciones de una comunidad universitaria sobre la participación activa en decisiones políticas. Se debate en torno a la necesidad de fomentar la responsabilidad social y la formación integral a través de la participación ciudadana. Los métodos para recabar la información fueron la revisión

* Parte de la construcción teórica de la investigación titulada "Observatorio Ciudadano de la Educación Superior en Antioquia, el caso de la Universidad de Antioquia" de la Vicerrectoría de investigación, proyecto CODI número 580 del 23 de julio de 2010 a 2016.

** Profesora titular investigadora. Universidad de Antioquia. Química Farmacéutica, especialista en atención farmacéutica y maestría en farmacología. Correo electrónico: flor. tobon@udea.edu.co ORCID: https://orcid.org/0000-0002-7386-1333

*** Profesor investigador. Facultad de Enfermería, Universidad de Antioquia, Medellín, Colombia. Antropólogo. Maestría y doctorado en salud pública. Correo electrónico: alirio. lopez@udea.edu.co ORCID: https://orcid.org/0000-0002-9667-6341

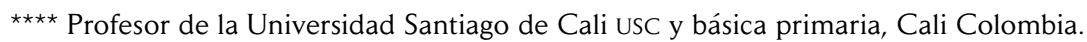
Licenciatura en Pedagogía Infantil. Maestría en Educación. Doctor en educación. Integrante del grupo de investigación Uni-Pluri/Universidad de Antioquia y de FORMACCE-UFBA/FACED. Correo electrónico: runan10@yahoo.com ORCID: https://orcid.org/0000-0003-1425-4776 
documental de un periódico y una revista universitarios entre 2005 a 2016 y grupos focales con representantes de las organizaciones universitarias reconocidas, a quienes se les consultó sobre su percepción acerca de la participación y la convivencia en la universidad. El análisis de la indagación sugiere una formación ciudadana insuficiente para promover la participación activa. Se observa que la convivencia y la participación en ámbitos universitarios es útil para generar procesos sociales con el fin de solucionar conflictos relacionados con problemáticas de orden local, nacional y global.

Palabras clave: participación; convivencia; responsabilidad social; políticas públicas educativas.

\section{ABSTRACT}

The objective is to present an exploratory-hermeneutical study on the perception of the representatives of a university community organizations about active participation in political decisions. The article shows the debates around the need to promote social responsibility and comprehensive training through citizen participation. The methods used were a documentary review of a university newspaper and magazine between 2005 and 2016 and focus groups with representatives of recognized university organizations, who were consulted about their perception of participation and coexistence in the university. The analysis of the inquiry suggests there is insufficient citizenship training to promote active participation. It is observed that coexistence and participation in university settings are useful to generate social processes to solve conflicts related to local, national, and global problems.

Keywords: Participation; coexistence; social responsibility; educational public policies.

\section{RESUMO}

O objetivo é refletir sobre um estudo exploratório hermenêutico sobre a percepção de representantes de organizações de uma comunidade universitária sobre a participação ativa nas decisões políticas. É debatida a necessidade de promover a responsabilidade social e a formação integral por meio da participação cidadã. Método: a) revisão documental de jornal e revista universitária entre 2005 e 2016; b) grupos focais com representantes de organizações universitárias reconhecidas, que foram consultados sobre a sua percepção de participação e convivência na universidade. A análise do inquérito sugere uma formação cidadã insuficiente para promover a participação ativa. Observa-se que a convivência e a participação em ambientes universitários são úteis para gerar processos sociais de resolução de conflitos relacionados a problemas locais, nacionais e globais.

Palavras-chave: participação; convivência; responsabilidade social; políticas públicas educacionais. 


\section{Introducción}

La participación ciudadana se concibe desde la misión, visión, objetivos, principios, valores, intereses comunes, contenidos e intereses de los actores sociales dentro de una institución u organización social. En opinión de Fresco (2005), se requiere fortalecer los leguajes diversos en espacios de participación y mantener una comunicación fluida que ayude a la cimentación de subjetividades optimistas para la construcción de la convivencia sana y de un tejido social incluyente.

En acercamiento a esta percepción, existen pocos estudios sobre la participación activa de los representantes gremiales, desde la perspectiva de derechos, en los órganos de decisión política de cualquier institución, en este caso universitarios, donde se conciba la participación activa como aprendizaje y reaprendizaje renovado que permita apropiación y aplicación de los principios de la democracia real en situaciones diferentes de la vida cotidiana; máxime, por el ejemplo, para aportar a la responsabilidad social de la formación integral de los ciudadanos.

El desafío de las autoridades responsables directas de la educación, la cultura, la salud y la justicia, entre otras esferas de la vida en sociedad, es hacer propuestas que mejoren y fortalezcan la educación integral, centrada en el ser humano, hacia el desarrollo de capacidades y habilidades filosóficas, teórico-prácticas y éticas que formen ciudadanos íntegros, para entender las situaciones complejas de la vida cotidiana en relación con la búsqueda de soluciones a las problemáticas sociales con innovación social hacia el progreso territorial con justicia social.

Por esto, la oportunidad y el reto son la construcción democrática de políticas públicas educativas (PPE) desde la perspectiva de derechos, en las que se conciba un modelo educativo de aprendizajes optimistas que promueva la apertura de espacios democrático-participativos de debate intersectorial en las decisiones que afectan a los ciudadanos en condiciones vulnerables. En este sentido, la responsabilidad social debe estar orientada por la conciencia colectiva y la apropiación de los mecanismos de organización de la democracia real inclusiva; es decir, la participación directa como una práctica cotidiana (Pellicer et al., 2016; Vallaeys, 2014; Nussbaum, 2012; Tobón \& López, 2011). 
La participación desde la responsabilidad social es una concepción objetiva amplia y profunda, es el sentido de una PPE que forme a los ciudadanos para lograr el equilibrio de la relación estrecha entre la traída de derecho-responsabilidad social-libertad; lo cual requiere desarrollar aprendizajes holísticos (Weil, 1993) que permitan empoderar a los actores académicos y sociales en la apertura permanente de espacios reflexivos participativos, donde se analicen problemáticas sociales locales conexas a lo local, lo nacional y lo global. Dicho análisis requiere del impulso de una PPE que forje capacidades y habilidades para procesar las necesidades colectivas insatisfechas, conexas a la convivencia de seres humanos diversos que actúan como sujetos-ciudadanos. Lo anterior, a través de intenciones, expresiones, hechos y subjetividades. Una misión y una visión, acompañadas de principios, valores, normas y leyes institucionales que deben ser proporcionales a las decisiones políticas que afectan a los ciudadanos.

De ahí la inquietud de conocer la percepción sobre la participación en órganos de decisión política, desde los actores de organizaciones reconocidas de una comunidad universitaria colombiana, analizando medios de expresión escrita y oral de los representantes de algunas organizaciones. Para ello, el estudio planteó los siguientes interrogantes: ¿cómo es la coordinación y articulación de las autoridades centrales de la Universidad de Antioquia con los sectores representantes gremiales de la comunidad universitaria para facilitar la participación en los órganos de decisión política? ¿De qué manera se promueve la participación activa de la comunidad universitaria? ¿Cómo se percibe la actitud y la práctica de la participación y la convivencia ciudadana como una PPE por autoridades educativas y organizaciones de la Universidad de Antioquia? A partir de estos interrogantes se desarrollaron las discusiones que se abordan a lo largo del presente artículo.

En este sentido, ¿cómo se explica la participación activa en órganos de decisión política? La respuesta se puede entender desde el alcance de las decisiones que afectan a las mayorías, mediante la educación-formación holística (Espino, s. f.), centrada en el desarrollo integral hacia la transformación dinámica de la sociedad. De este modo, la participación en órganos de decisión política se debe soportar en un marco teórico 
científico-filosófico, para ejecutar el plan educativo integral (PEI), hacia la transformación social.

Las categorías centrales de análisis de este estudio son la participación y la convivencia en el marco de la PPE universitaria. Según Uribe (2011) y Landaeta (2006), estas son instrumentos para desarrollar la interacción humanitaria entre los ciudadanos universitarios y la construcción del tejido social. El marco de un Estado social de derecho (ESD) debe establecer espacios pedagógicos permanentes de comunicación, reflexión y discusión, que permitan convivir en comunidad y suscitar el bienestar individual y colectivo. La participación en las decisiones políticas que afectan la convivencia es un instrumento democrático para que las organizaciones forjen prácticas adecuadas de persuasión, capacitación popular y acciones efectivas de impacto social.

Tanto la participación activa como la convivencia están unidas al desarrollo humano y territorial sostenible desde la equidad y la justicia. El contenido teórico-filosófico amplio de la educación-formacióndesarrollo integral para la participación activa brinda aprendizajes holísticos, sustentados en el equilibrio entre la libertad, los derechos y los deberes de los ciudadanos autorregulados, consagrados en la Carta Política (CP) colombiana. Según Parra (2006, 2012), S. A. (2006) y Vasco (2010), existe relación entre la democracia y la PPE, concebida más allá de intereses particulares. En este sentido, se requiere de un plan curricular centrado en la formación del ser humano. La participación pluralista institucional debe fomentar la resiliencia para el cambio social en armonía con la naturaleza.

\section{Metodología}

Estudio cualitativo de enfoque fenomenológico-hermenéutico, cuyo propósito fue explorar el concepto político de la participación y la convivencia de empleados, profesores, estudiantes, egresados y coordinadores de bienestar de la Universidad de Antioquia en dos etapas. En la primera fase, se realizó una revisión documental de la revista Debates y el suplemento Almater entre el periodo 2005-2016 y algunas normas relacionadas con el tema de la convivencia. Se seleccionaron 
160 artículos de temas que la Universidad de Antioquia divulga como acciones de participación activa. De estos, 59 se encontraron relacionados con la participación y la convivencia. De estos se hizo transcripción textual, codificación, categorización y análisis cualitativo de tipo fenomenológico-interpretativo.

En la segunda fase, se aplicó una entrevista semiestructurada de dos preguntas abiertas a representantes de 17 organizaciones reconocidas, sobre las acciones y procedimientos que desarrollan para promover la política de la participación. Cada una de ellas se constituyó en un grupo focal, al cual se le plantearon las siguientes preguntas:

1. ¿Qué acciones políticas realizan para promover la convivencia?

2. ¿Cómo desarrollan las actividades que ejecutan para promover la política de la participación activa estudiantil y de todos los estamentos?

Los testimonios de los representantes de las organizaciones reconocidas por la comunidad académica de la Universidad de Antioquia (17 grupos focales) se transcribieron en forma textual en el programa Excel. Se identificaron códigos y categorías consideradas de mayor frecuencia e importancia, entre otras, y se realizó un análisis cualitativo de tipo fenomenológico-interpretativo.

\section{Hallazgos y discusión}

El análisis de los 59 documentos seleccionados de la revista Debates y el suplemento Almater sobre percepción de los actores académicos entorno a la participación permitió sistematizar los hallazgos en cuatro categorías, de mayor importancia y frecuencia:
a) La participación en torno a la investigación
b) La participación desde el medio radial de comunicación universitaria
c) La convivencia ciudadana
d) La participación desde del encuentro con el cine 


\section{La participación en torno a la investigación}

Las autoridades universitarias conciben la participación democrática como la convocatoria abierta a presentar proyectos de investigación y el indicador del aumento de la participación de la universidad como líder en la creación e impulso de grupos de investigación estudiantil y profesoral, en el ámbito local, regional, nacional e internacional de todas las áreas académicas, incluyendo las ciencias sociales y humanas.

En opinión de Mahecha $(2009 ; 2011)$, la investigación como parte de los ejes misionales de la universidad, junto con la docencia, la extensión y la administración, debe articularse al plan de trabajo docente en cada unidad académica. No obstante, en la práctica de algunos ámbitos universitarios, no es evidente la equidad de condiciones para acceder a grupos de investigación y recursos para realizar investigaciones, pues se privilegia el apoyo a investigaciones de corte empírico-analítico, sobre las investigaciones cualitativas de enfoque hermenéutico.

El interés manifiesto de la investigación positivista de desarrollar conocimientos estrictamente objetivos ha negado la importancia del estudio de fenómenos sociales inconmensurables. En este sentido, la participación debe comprometer a los actores académicos universitarios como abiertos al diálogo interdisciplinario. Desde una perspectiva holística, la investigación en el ámbito de la educación superior debe ser concebida para garantizar que el interés por investigar sobre un tema particular, concretado en el marco de procesos democráticos, incluyentes y participativos. Asimismo, la identificación de un problema social que amerita ser investigado desde enfoques hermenéuticos debe ser valorada y evaluada desde marcos argumentativos y no de ponderaciones, sino sobre el impacto humano y social, apoyado en parámetros cuantitativos, cualitativos o mixtos.

\section{Participación desde el medio radial de comunicación universitaria}

El principal medio radial de la Universidad de Antioquia es la Emisora Cultural. Esta cuenta con programas de extensión enlazados a otras cinco emisoras en puntos estratégicos de la geografía antioqueña. Se concibe como un medio de participación amplio que enaltece la 
conexión radial con la población local y regional. Se trata de una estrategia educativa y cultural innovadora de extensión e impacto social en las comunidades regionales. Es posible afirmar que el medio radial logra cierta participación ciudadana si cumple con el reto de crear medios de comunicación educativa que mejoren los aprendizajes integrales y aporten a la formación ciudadana y la justicia social (Marulanda, 2012; Rincón Castellanos, 2006; Franco 2005).

Para Freire (2010) la educación es comunicación -diálogo- en la medida en que no es la transferencia del saber, sino un encuentro de sujetos interlocutores, un diálogo de saberes que tiene la intencionalidad de posicionar el discurso académico de la participación en los órganos de decisión política de la universidad, desde los ámbitos regional y nacional. Se plantea, entonces, el reto de contribuir a formar ciudadanos para la participación activa en órganos de decisión política. Para tal efecto, se necesita diferenciar entre difusión, información y educación.

Desde la mirada de Nieto (2013), el medio radial de comunicación facilita cierta participación, pero exige formas democráticas organizadas desde la interdisciplinariedad, la multiculturalidad y la intersectorialidad. De ello se puede colegir la importancia de ampliar los contenidos del espacio radial al debate académico con las autoridades responsables de las decisiones. La oportunidad y el reto de la comunicación radial educativa, en cercanía al pensamiento de Castro (2007) y Cortés (2011), implica acciones y procedimientos integrados y regulados al contexto de las realidades sociales. En dicho contexto, la comunidad universitaria tiene un papel político en la divulgación de la información académica y en el fomento de la educación holística (Yus Ramos, 2001), conexa a la salud y la vida, con el propósito de ayudar a la satisfacción de las necesidades básicas humanas.

El acercamiento a la opinión de Franco (2005), Mascarozf (2008), Moreno y Vergara $(2006)$ y Restrepo $(2006$; 2011) permite inferir que la responsabilidad social de la información y la comunicación como un bien público, en derecho, se determina por la contribución que se haga a la cimentación del conocimiento humano y a la transformación de la sociedad. Mediante un lenguaje que eduque en forma clara, precisa y completa. La participación directa en las decisiones de impacto social, requiere la creación de espacios de raciocinio académico-político, redes 
de análisis y discusión permanente de las realidades sociales desde lo académico, lo político-económico, lo sociocultural, lo tecnológico y lo ambiental.

\section{La convivencia ciudadana en la universidad}

Algunos artículos señalan proyectos desarrollados por la universidad en equipo con la alcaldía de Medellín, Colombia, integrados a una comunidad objetivo. El más evidente es el proyecto Mujeres Talento, que engrandece un modelo de mujer, alternativo al estándar del mercado. El propósito es educar a la mujer en la necesidad de superar dos puntos negativos para su desarrollo integral sostenible: uno, no debe ser centro de consumo y dos, debe convertirse en el tipo de mujer inteligente y emprendedora que supera la sombra de la misoginia.

Acorde al pensamiento de Pérez (2012), este proyecto es una forma de imprimirle valor a la mujer; además, es un avance hacia la construcción de la convivencia. No obstante, desde la opinión de Veiga (2007), se interpreta inexistencia de otros planes, programas y proyectos integrales continuos en contexto sobre cómo alcanzar una convivencia óptima para todos. En los enfoques de Ossa Escobar (2009) y Galeano Londoño (2010), se observa que estos proyectos exigen consenso desde una biopolítica de inclusión: validar el impacto social en el tiempo y el permanente carácter institucional. Esto permite pensar que las instituciones educativas están en deuda con la sociedad, en cuanto a la formación integral en la participación en las decisiones que afectan a las comunidades y en la ciudadanía sostenible.

De ahí lo ineludible de la responsabilidad social de todos los actores académicos de construir juntos subjetividades optimistas desde el aula de clase, con y para las comunidades más necesitadas que requieren acompañamiento psicosocial. Un compromiso democrático de educar para la participación directa y la convivencia. En este sentido, resulta importante forjar el desarrollo del pensamiento político transdisciplinar y multicultural que permita a los estudiantes, académicos y ciudadanos ser partícipes en las decisiones políticas que los afectan, con sentido de pertenencia por el territorio en cada contexto. 


\section{Participación desde el encuentro con el cine}

Esta categoría hace referencia a un programa que funciona desde hace 20 años. Este busca establecer un vínculo entre los estudiantes y la dimensión cultural en el entorno universitario. Se trata de una concepción integral que aporte a los procesos de convivencia y mejoramiento de las relaciones entre los integrantes de la comunidad universitaria a través del arte, sobre la base de la introducción de la cultura en el plan de desarrollo universitario, en perspectiva de derechos.

El encuentro con el cine pretende, a través de cine foros, ampliar la visión de la cultura universitaria de una manera holística, unida a la vida cotidiana del universitario. Sin embargo, solo logra la atención de una minoría de la población estudiantil. En este sentido, amerita comentar dos asuntos que manifiesta Galeano Londoño (2007a; 2007b). El primero, relacionado con pensar estrategias educativas psicopedagógicas y sociales encaminadas a que los estudiantes vean la importancia de la educación de calidad, ligada al arte con proyección social. El segundo punto, relacionado con el desafío de educar en aprender, desaprender y reaprender para el cambio de paradigma, exige de las autoridades consciencia en la selección de docentes capacitados y habilidosos, con un perfil académico-humano integral, acompañado de formación permanente.

De otro lado, este análisis encontró otra categoría emergente de contenido sobre participación y convivencia en torno al proyecto Programa de Guía Cultural. Este se percibe como un plan institucional de participación ciudadana, que asume el desarrollo de la diversidad cultural como una parte de la dimensión política. Al respecto, Mira (2013) y Rendón (2010) explican el deber de la universidad de educar-formar en la práctica de la controversia, en diálogo de saberes para superar situaciones de crisis. Según Aparici (2010), ser dialógico constante de la realidad es empeñarse en la transformación, no invadir ni manipular ni imponer consignas.

En perspectiva de derechos, la universidad con este proyecto muestra un avance, pero debe crear otras experiencias lúdicas por procesos continuos, mediante el desarrollo integral de estos programas culturales que forjen una práctica para fortalecer la educación con calidad humana, 
del mismo modo que estimule la convivencia y la participación activa de los integrantes de la comunidad universitaria.

\section{Hallazgos de la segunda etapa}

Las entrevistas a las organizaciones reconocidas en la universidad (17 grupos focales) se relacionan en las tablas 1 y 2 (anexo). Los datos reunidos en ellas sugieren que los representantes de la comunidad académica universitaria consultada expresan una concepción sobre la participación activa que refleja una idea de democracia. Esta se aproxima a los hallazgos de la primera etapa y al análisis de la revisión documental de contenidos en torno a la participación activa. Llama la atención la insistencia en los conceptos de estas organizaciones consultadas sobre participación y convivencia en el marco de un ESD, al concebir procedimientos y actividades simples que realizan, como medios de promoción a la participación en órganos de decisión. Esto sugiere que la participación de las organizaciones en los órganos de difusión de la Universidad de Antioquia se acerca más a la concepción de una democracia representativa.

Tabla 1. Concepciones de los representantes de asociaciones de la Universidad de Antioquia en torno a la participación y convivencia

\begin{tabular}{|c|c|c|}
\hline Asociación & Convivencia & Participación \\
\hline Afrodescendientes & $\begin{array}{l}\text { - Charlas foros de territorialidad. } \\
\text { - Murales. } \\
\text { - Ollas comunitarias. }\end{array}$ & $\begin{array}{l}\text { - Actividades para promover la } \\
\text { sana convivencia y fomentar } \\
\text { la participación, cada } 21 \\
\text { de mayo, semana de la } \\
\text { afrocolombianidad y en el mes } \\
\text { de octubre, identidades. }\end{array}$ \\
\hline Sindicato & $\begin{array}{l}\text { - Asambleas, donde se tratan } \\
\text { puntos de bienestar común de } \\
\text { la comunidad universitaria. }\end{array}$ & $\begin{array}{l}\text { - Colaboración con implementos } \\
\text { o materiales para actividades } \\
\text { estudiantiles y demás gremios. }\end{array}$ \\
\hline SINTRAUNICOL & Boletines & Reuniones \\
\hline Tiempo Libre & $\begin{array}{l}\text { - Torneos interfacultades en } \\
\text { todas las categorías: fútbol, } \\
\text { básquet, voleibol, tejo, softbol, } \\
\text { entre otras; entre estudiantes, } \\
\text { profesores y empleados. }\end{array}$ & $\begin{array}{l}\text { - Todas las actividades que se } \\
\text { realizan son para promover } \\
\text { la sana convivencia y la } \\
\text { participación. }\end{array}$ \\
\hline
\end{tabular}




\begin{tabular}{|l|l|l|}
\hline \multicolumn{1}{|c|}{ Asociación } & \multicolumn{1}{|c|}{ Convivencia } & \multicolumn{1}{c|}{ Participación } \\
\hline $\begin{array}{l}\text { Asociación } \\
\text { Pensionados } \\
\text { Jubilados }\end{array}$ & - Asambleas. & $\begin{array}{l}\text { Se brinda implementos y apoyo } \\
\text { para las diferentes actividades a } \\
\text { los estudiantes. }\end{array}$ \\
\hline $\begin{array}{l}\text { Asociación } \\
\text { de profesores } \\
\text { (ASOPRUDEA) }\end{array}$ & - Foros. & $\begin{array}{l}\text { Impulsar asamblea y reuniones } \\
\text { de la Multiestamentaria. }\end{array}$ \\
\hline
\end{tabular}

Tabla 2. Concepciones de los representantes de las oficinas de bienestar estudiantil de facultades acerca de la participación y convivencia

\begin{tabular}{|c|c|c|}
\hline Asociación & Convivencia & Participación \\
\hline Salud Pública & $\begin{array}{l}\text { - Todo está enfocado al bienestar } \\
\text { universitario. }\end{array}$ & $\begin{array}{l}\text { - Carteles. } \\
\text { - Medios electrónicos. }\end{array}$ \\
\hline Medicina & $\begin{array}{l}\text { - La oficina de bienestar de la } \\
\text { facultad se encarga. } \\
\text { - Tienen poco conocimiento. }\end{array}$ & $\begin{array}{l}\text { - Se colabora con todo lo } \\
\text { relacionado con el bienestar. }\end{array}$ \\
\hline Odontología & $\begin{array}{l}\text { - Actividades trazadas por la } \\
\text { facultad. } \\
\text { - Acciones sugeridas por } \\
\text { bienestar universitario. }\end{array}$ & $\begin{array}{l}\text { - Asambleas. } \\
\text { - Foros. } \\
\text { - Carteleras. } \\
\text { - Blog de la facultad. }\end{array}$ \\
\hline Enfermería & $\begin{array}{l}\text { Actividades de tipo: } \\
\text { - Cultural. } \\
\text { - Deportiva. } \\
\text { - Concurso fotográfico. } \\
\text { - Fomento del trabajo en equipo. }\end{array}$ & $\begin{array}{l}\text { - Sensibilización en charlas. } \\
\text { - Asambleas. } \\
\text { - Consejo del área de la salud en } \\
\text { debate para implementar. }\end{array}$ \\
\hline $\begin{array}{l}\text { Ciencias Sociales } \\
\text { y Humanas }\end{array}$ & $\begin{array}{l}\text { - Grupos de estudios. } \\
\text { - Cine foros. } \\
\text { - Ollas comunitarias. } \\
\text { - Eventos que ayuden a } \\
\text { conglomerar los estudiantes. }\end{array}$ & $\begin{array}{l}\text { - Aula crítica. } \\
\text { - Murales. } \\
\text { - Cátedra pública apoyada por la } \\
\text { decanatura. }\end{array}$ \\
\hline Derecho & $\begin{array}{l}\text { - Un espacio propio para estudiar, } \\
\text { prestar textos y fomentar las } \\
\text { actividades académicas. }\end{array}$ & $\begin{array}{l}\text { - Un espacio propio abierto a la } \\
\text { comunidad universitaria. }\end{array}$ \\
\hline Ingenierías & $\begin{array}{l}\text { - Orientación a los compañeros } \\
\text { con problemas académicos. } \\
\text { - Se basa en el diálogo. } \\
\text { - Busca solucionar dificultades de } \\
\text { la facultad y de la universidad. }\end{array}$ & $\begin{array}{l}\text { - Brinda información sobre } \\
\text { los problemas que padece la } \\
\text { Universidad. } \\
\text { - Se fomenta un buen debate } \\
\text { sobre los problemas. }\end{array}$ \\
\hline
\end{tabular}




\begin{tabular}{|c|c|c|}
\hline Asociación & Convivencia & Participación \\
\hline $\begin{array}{l}\text { Ciencias Exactas } \\
\text { y Naturales }\end{array}$ & $\begin{array}{l}\text { - Solo promueve el estudio y las } \\
\text { actividades académicas. }\end{array}$ & - No respondieron. \\
\hline $\begin{array}{l}\text { Facultad de } \\
\text { Economía }\end{array}$ & $\begin{array}{l}\text { - No respondieron por la } \\
\text { situación de violencias en la } \\
\text { universidad. }\end{array}$ & - No respondieron. \\
\hline Educación Física & $\begin{array}{l}\text { - Se fomenta todas las actividades } \\
\text { programadas por bienestar } \\
\text { de la facultad y de bienestar } \\
\text { universitario como torneos de } \\
\text { fútbol y demás categorías. } \\
\text { - En las actividades de la } \\
\text { asamblea general de estudiantes } \\
\text { y de la facultad. }\end{array}$ & $\begin{array}{l}\text { - Invita a los estudiantes } \\
\text { a participar en todas las } \\
\text { actividades que realiza la } \\
\text { facultad y en las convocadas } \\
\text { por la asamblea de estudiantes. }\end{array}$ \\
\hline $\begin{array}{l}\text { Nutrición y } \\
\text { Dietética }\end{array}$ & $\begin{array}{l}\text { - Promueve actividades que } \\
\text { vayan en pro de la salud y el } \\
\text { bienestar de la comunidad: } \\
\text { charlas, talleres, entre otras. }\end{array}$ & $\begin{array}{l}\text { - Invita a las actividades que se } \\
\text { programen en la escuela o en la } \\
\text { ciudadela robledo. }\end{array}$ \\
\hline $\begin{array}{l}\text { Zootecnia y } \\
\text { Veterinaria }\end{array}$ & $\begin{array}{l}\text { - Realiza jornadas de vacunación } \\
\text { para mascotas y otros servicios } \\
\text { solidarios. } \\
\text { - Participa de las actividades de } \\
\text { bienestar de la facultad. }\end{array}$ & $\begin{array}{l}\text { - Invita a los compañeros a } \\
\text { participar en las jornadas que se } \\
\text { programen. }\end{array}$ \\
\hline
\end{tabular}

La noción de algunos representantes universitarios en los órganos de decisión en torno a las dimensiones de la participación en las decisiones institucionales, en perspectiva de derechos, se aleja del significado amplio de la participación activa. En este sentido, se requiere de indicadores de participación en las decisiones que den cuenta de cómo procesar situaciones críticas de forma oportuna y efectiva de modo permanente; por ejemplo, acordar cómo intervenir variables psicosociales críticas como el rendimiento deficiente de muchos estudiantes y empleados; el aumento exponencial del consumo de psicotrópicos ilegales; la deserción estudiantil; las violencias diversas, y la incursión de la fuerza pública en los campus. Situaciones críticas que requieren acciones y procedimientos académicos e investigativos continuos, hacia la innovación de la educación cívica integral en constructos de la responsabilidad social y de una convivencia sana y sostenible para tejer resiliencia juntos.

En afinidad con el pensamiento de Pineda (2014) y Gómez (2012), estos hallazgos se alejan de la concepción teórica, social, filosófica, 
política y de la praxis democrática real. Un asunto que debe ser materia de interés para todos los involucrados, ya que la falta de claridad sobre el significado de la participación activa limita la responsabilidad social de los líderes de exigir una democracia real que motive acciones y procedimientos de hechos en defensa de los derechos humanos y la ciudadanía. Esta situación puede interpretarse como una necesidad de formación política que debería dotar de capacidades y habilidades a los ciudadanos para participar en los órganos de decisiones.

Esta realidad, en afinidad con el pensamiento de Rubiano (2012) y S. A. (2007), se explica como una crisis en la representación de los estamentos. Existe un escaso control político de los ciudadanos en las decisiones de impacto social de los gobernantes. Asimismo, para Cortés (2005; 2011), Franco (2006) y Nieto (2012), esta percepción permite pensar que se demanda evolución de la educación integral sobre la base del sentido de una PPE beneficiosa que conciba la práctica de posibilidades alternativas (PPA) en el marco de los procesos complejos de lo biosociopolítico coherente con el saber hacer en el deber ser de la ciencia, la tecnología y la innovación social.

Se trata de renovar el sentido de la concepción de una biosociopolítica centrada en el derecho a la vida con dignidad, que permita el desarrollo holístico sistemático del ser humano inmerso en un mundo globalizado. La construcción de subjetividades sobre la base de participación estructurada y organizada en los órganos de decisión política debe exigir garantía y protección de los derechos humanos, como el derecho a la gratuidad de la educación superior de los jóvenes con calidad e inclusión social, para la construcción de la convivencia y la dignidad humana con calidad de vida.

En concordancia con Rendón (2010) y Medina (2013), se observa que el intento de cierta organización gremial en diálogo de saberes entre los representantes de varios estamentos, multiestamentaria, está en coherencia con S.A. (2012): pretende motivar la práctica en la comunidad universitaria de vivir su propia ciudadanía desde el horizonte de la conexión de la triada de compromisos-derechos-libertades, un espacio dinámico de reflexión y discusión en construcción de subjetividades; un proceso complejo de desarrollo de cultura ciudadana, que busca intereses comunes para el control político de las decisiones de las 
autoridades universitarias. Sin embargo, la multiestamentaria requiere más organización y coordinación para consolidarse. Sus representantes tienen el reto de fortalecerse para lograr una mayor y mejor participación directa en el control político.

Para el logro de este desafío, sumando al pensamiento de Orozco (2011) y Ortega y Domínguez (2001), se requiere el compromiso con la misión de la organización, máxime de las instituciones públicas; por ejemplo, de ser un referente en valores éticos y morales. Estos deben primar sobre la letra muerta en el papel y superar la praxis retórica y demagógica corporativa de autoridades gubernamentales que no favorece la participación activa de todas las voces diversas de los actores representantes en los espacios donde se toman las decisiones de interés colectivo.

Los campus deben innovar la educación integral biopolítica y optimista para el cambio de paradigmas ambiguos e inconsistentes, un reto para lograr la armonía virtuosa de intereses comunes entre la interrelación dinámica de la universidad con el Estado y la sociedad civil, tanto en el ámbito local como mundial. Este ideal se acerca al pensamiento de Ríos (2013), S.A. (2012) y Villamil (2010) en resistencia al autoritarismo que no aporta de forma real a la solución de las necesidades básicas de los más necesitados.

Acorde al saber de Rincón Castellanos (2006), las actitudes y prácticas democráticas de las autoridades son aquellas orientadas a derechos civiles (libertad individual), políticas (participación activa en las decisiones política) y sociales (trabajo, educación, salud, vivienda). Lo anterior se evidencia en hechos cotidianos que afirman la responsabilidad moral, ética, jurídica y social de los responsables directos de las decisiones políticas para el bienestar común. Por el honor que les dieron de ser líderes (no jefes), gestores sociales de acciones de PPE, emisores del gobierno en el marco de un ESD. En este sentido, se deben facilitar condiciones equilibradas de participación directa en las decisiones de tipo administrativo, académico, social, cultural, financiero, político y jurídico.

En acercamiento a la opinión de Franco (2006), a las autoridades responsables directas de las universidades, en un ESD, les corresponde propiciar las condiciones de diálogo de saberes necesarias que faciliten una participación activa y diversa para el análisis profundo de 
las complejas realidades universitarias. Estas deben ser analizadas a profundidad por un equipo intersectorial, capacitado en el diálogo de saberes de forma transdisciplinar-multicultural; esto implica habilidad objetiva institucional para ser un emisor-receptor y escuchar-hablar y proponer la solución de las problemáticas desde aspectos universitarios y comunitarios amplios. La misión y razón de ser de las universidades es formar ciudadanía, mediante la participación pluralista institucional que procure el surgimiento de líderes íntegros y grupos y movimientos diversos para el consenso relacionado con la distribución equitativa de recursos materiales, los servicios simbólicos y de talento humano capacitado y con habilidades en el saber-hacer en el deber ser oportuno $y$ efectivo en lo cotidiano.

En este sentido, los ideales de Orozco (2011) y Ortega y Domínguez (2001) sugieren que las autoridades universitarias responsables directas de las decisiones tienen tácita la democracia real: una responsabilidad social, política, jurídica, ética y moral de ser referente para forjar la participación directa de la ciudadanía. Sin embargo, en ocasiones, la administración de las universidades públicas se encuentra mayormente orientada a seguir las prescripciones corporativas de la democracia representativa y el pragmatismo razonado del neoliberalismo. Una perspectiva opuesta a la participación directa y activa, ${ }_{1}^{1}$ basada en la CP y en el ESD, cuyos principios universales son la favorabilidad, equidad, oportunidad, transparencia y proporcionalidad, entre otras. Estos principios deben ser objetivos y visibles en beneficio de los seres humanos, la institución y la sociedad.

Asimismo, las autoridades responsables directas de las decisiones de interés público deben tener la disposición de ponerse del lado de los actores académicos para facilitarles espacios incluyentes y las condiciones necesarias para el análisis y la discusión amplia de los problemas humanos, sociales y ambientales, bajo el sentido crítico intersectorial,

1 En este texto se concibe a los espacios incluyentes como las condiciones necesarias para la discusión amplia y profunda de los criterios de legalidad, legitimidad y reciprocidad en la decisiones académicas, político-económicas, socioculturales, tecnológicas y ambientales, entre otras, para acceder a la financiación de los proyectos e incidir en las decisiones que orientan a la universidad pública que desea todos los estamentos de la comunidad académica, en perspectiva de derechos y necesidades humanas por transformar hacia la ambición de una cultura del cambio social benéfico para todos y todo. 
donde se practique el ejercicio de la ciudadanía en el marco de los criterios de legalidad, legitimidad y reciprocidad en las decisiones de impacto académico, político, económico, sociocultural, tecnológico y ambiental, entre otros.

La participación activa se entiende a partir de las hipótesis de Villamil (2010) y S. A. (2012). La premisa de la gestión democrática real de las mayorías en los órganos de decisión que afectan a la sociedad es la ruta de la construcción de ciudadanía. Esta se concibe como un modo de ser y actuar aprendido o adquirido para el desarrollo del sentido crítico. Una herramienta educativa indispensable para afianzar la democracia a través de la fuerza de los argumentos de los representantes de los estamentos e influir en las decisiones de interés colectivo. Una forma de resistencia civil por el bien común se refiere a la construcción de relaciones intersubjetivas desde miradas pluralistas para la intervención de las necesidades de subsistencia y axiológicas básicas humanas.

En opinión de Veiga (2006), Vasco (2010), Uribe (2011) y Medina (2013), se concibe el logro de la convivencia como parte de la democracia real que favorece la comunicación bidireccional, efectiva y oportuna. Esta acoge las autonecesidades, las necesidades del otro y las necesidades del todo como un pacto responsable de todo acuerdo que construya comunidad y tejido social. Asimismo, la convivencia se percibe como un refugio y un deseo asentada en una ética y moralidad consciente de aprendizajes para el desarrollo de la educación, la formación y el desarrollo integral sostenible con calidad e inclusión.

El análisis de este soporte teórico y científico-filosófico de carácter fenomenológico-interpretativo sobre la concepción de los contenidos de la participación activa de los representantes gremiales en las decisiones políticas que afectan a la sociedad y la convivencia sana deben ser una prioridad de los representantes de los gobiernos. Además, ellos deben considerar la educación cívica integral como los pilares esenciales para el desarrollo humano integral sostenible y la construcción de capital social. Hacia el futuro se debe pensar otro modelo educativo y formativo de aprendizajes que permita forjar constructos de la participación en democracia real, donde la esencia sea la sana convivencia para la transformación social y el progreso territorial (Ortega \& Domínguez, 2001; van Gingek, 2005; Orozco, 2011; Tobón et al., 2012). Esta actitud y 
práctica ayudan a resolver las causas estructurales que inducen a violencias que afectan la convivencia en la vida académica.

\section{Conclusión}

Este análisis fenomenológico-hermenéutico sugiere que la comunidad universitaria objeto de estudio expresa la necesidad de una mayor participación en el control político. Existen expectativas de innovar: concebir un modelo educativo integral con calidad efectiva y oportuna a muy temprana edad, sobre la base de la concepción de aprendizajes flexibles, transversales al plan curricular, para forjar constructos de contenidos en torno a la participación activa desde el aula de clase y al aprender a convivir con sentido crítico. Esto requiere de la caracterización de las causas determinantes de las problemáticas de los integrantes de la comunidad universitaria. Estas se deben plasmar en planes, programas y proyectos en el marco del plan de desarrollo de la universidad, local y global. Un reto que demanda de todos la reestructuración e innovación del modelo educativo hacia la construcción optimista de visiones participativas reales de la sociedad.

\section{Referencias}

Aparici, R., E Otros (2010). Educomunicacion más allá del 2.0. Gedisa.

Atehortúa Castro, L. A. (2007). El papel político de la formación integral y algunas consideraciones sobre educación y política. Revista Debates, (46), 53-64.

Cortés, F. (2005). Justicia global, derechos humanos y responsabilidad. Revista Debates, (42), 19-28.

Cortés, F. (2011). Democracia y educación. Revista Debates, (59), 18-25.

Espino de Lara, R. (s. f.). Educación holista. Revista Iberoamericana de Educación. https://rieoei.org/historico/deloslectores/330Espino.pdf

Franco, V. L. (2006). Justicia retributiva y responsabilidad política: una respuesta al dilema transicional. Revista Debates, (45), 10-24. 
Franco, G. (2005). La función social de la comunicación. Periódico Alma Mater, 22.

Freire, P. (2010). ¿Educación o extensión? La concientización en el medio rural. Siglo XXI Editores.

Fresco, W. (2005). Entre la sed de vida y la sed de ganancias. Revista Debates, (40), 56- 63.

van Gingek, H. (2005). Re-pensando la Universidad para el siglo XXI. Revista Debates, (42), 34-47.

Gómez, R. (2012). Cambio corporativo. Revista Debates, (63), 22-25.

Landaeta, J. (2006). Construcción del tejido social y la convivencia ciudadana. Revista Debates, (41), 17-23.

Galeano Londoño, J. R. (2007a). La responsabilidad social en la formación y selección de los docentes: hábitos y competencias. Revista Debates, (46), 45-52.

Galeano Londoño, J. R. (2007b). Una propuesta de Re-significación de la Educación para los antioqueños desde los PEI. Revista Debates, (48), 56-63.

Galeano Londoño, J. R. (2010). La formación ciudadana se encuentra en saldo rojo y no por falta de normas. Revista Debates, (57), 68-71.

Mahecha, J. (2009). A propósito de la nueva clasificación de grupos de investigación en Colombia. Revista Debates, (53), 42-51.

Mahecha, J. (2011). Sistema Universitario de Investigación y Libertad de Cátedra. Revista Debates, (58), 60-63.

Marulanda, D. (2012). Una Antioquia más educada. Retos para la Educación Superior y las universidades. Revista Debates, (61), 64-71.

Mascarozf, A. (2008). Comunicación pública. Revista Debates, (49), 46-49.

Medina, M. (2013). La comunidad universitaria, la variable estratégica de intervención en el conflicto universitario. Revista Debates, (64), 9-12.

Mira, H. (2013). La universidad debe formar en la práctica del diálogo y la controversia. Revista Debates, (64), 13-16.

Moreno, A., \& Vergara, D. (2006). Lenguaje, educación y sociedad. Revista Debates, (45), 80-83.

Nieto, J. (2012). ¿Por qué sí es posible que la universidad pública se gobierne democráticamente? Revista Debates, (62), 34-37.

Nieto, J. (2012). La autonomía del conocimiento vivo en la universidadmetrópolis. Revista Debates, (62), 69-74.

Nieto, J. (2013). Paz: participación y democracia. Revista Debates, (65), 2-9.

Orozco, L. (2011). La misión de la universidad pública: principios ético-políticos. Revista Debates, (60), 2-13. 
Nussbaum, M. C. (2012). Crear capacidades. Propuesta para el desarrollo humano. Paidós.

Ortega, P., E Mínguez, R. (Eds.). (2001). Una educación moral ¿para qué?: La educación moral del ciudadano de hoy. Paidós, SAICF.

Ossa Escobar, C. (2009). No concibo una universidad pública sin el compromiso de transformar la sociedad. Revista Debates, (52), 24-28.

Parra, A. (2006). La Constitución de 1991 y el derecho a la educación. Revista Debates, (44), 17-22.

Parra, T. (2012). La acción colectiva como participación. Revista Debates, (61), 20-23.

Pellicer, V., Belda, S., López, A., E Boni, A. (2016). Exploring connections between social innovation, grassroots processes and human development: An analysis of alternative food networks in the city of Valencia (Spain). Ingenio (CSIC-UPV) Working Paper Series 2016-04. http://www.ingenio. upv.es/sites/default/files/working-paper/2016-04.pdf

Pérez, W. (2012). Comentarios sobre seguridad y convivencia. Revista Debates, (63), 18-21.

Pineda, R. (2014). Guillermo Hoyos-Vásquez: la formación de ciudadanos en la construcción de la democracia en Colombia. Magis, 6(13), 161-172. https://doi.org/10.11144/Javeriana.m6-13.ghfc

Rendón, C. E. (2010). La crisis de la universidad como crisis de su idea. Revista Debates, (57), 53-61.

Restrepo, J. (2011). La información como bien público. Revista Debates, (58), 28-34

Restrepo, L. (2006). Comunicación y organización palabra y vida. Revista Debates, (41), 24-31.

Rincón Castellanos, C. A. (2006). La noble utopía de la comunidad académica. Revista Debates, (43), 42-45.

Ríos, A. (2013). ¿Nos violenta la protesta? Revista Debates, (65), 28-32.

Rubiano R. (2012). Universidad, crisis de sentido y des-institucionalización en la actualidad. Revista Debates, (61), 46-55.

S. A. (2006). Educación pública, inclusión y derechos humanos. Revista Debates, (44), 23-24.

S. A. (2007). El papel de la universidad en el equilibrio global. Revista Debates, (46), 36-38.

S. A. (2012). Las Universidades Latinoamericanas ante los rankings internacionales. Impactos - Alcances - Límites. Revista Debates, (62), 48-56. 
S. A. (2012). II Jornadas políticas Multiestamentaria por la defensa de la universidad pública. Revista Debates, (63), 60-88.

Tobón, F., \& López, L. (2011). El desarrollo a escala humana un referente para el diseño de planes de desarrollo local. En I. Lopera \& F. Builes (Eds). Abriendo espacios flexibles en la escuela. Universidad de Antioquia.

Tobón, F., Mejía, M., \& Gutiérrez, P. (2012). Un mundo mejor es posible: Educación humanista hacia la búsqueda del ser humano en la Atención Farmacéutica y en la ciudadanía. Editorial Académica Española.

Uribe, R. (2011). Reflexiones sobre democracia universitaria. Revista Debates, (60), $48-55$.

Vallaeys, F. (2014). La responsabilidad social universitaria: un nuevo modelo universitario contra la mercantilización. Revista Iberoamericana de Educación Superior, 5(12). http://www.scielo.org.mx/scielo.php?pid=S2007$28722014000100006 \&$ script=sci_arttext $\mathrm{ft}$ lng $=$ pt

Vasco, J. (2010). La convivencia y la participación en la Universidad. Revista Debates, (56), 6-13.

Veiga, E. J. (2007). Los observatorios de la convivencia ¿Cómo alcanzar la mejor convivencia? http://dialnet.unirioja.es/servlet/articulo?codigo $=3120832$

Villamil, E. (2010). Modelo de gobierno universitario colombiano, el más antidemocrático de América Latina. Revista Debates, (55), 26-29.

Weil, P. (1993). Holística: una nueva visión y abordaje de lo real. Editorial San Pablo.

Yus Ramos, R. (2001). Educación integral: una educación holística para el siglo XXI. Tomo 1-2. Desclée de Brouwer S. A. 